\title{
Uma Análise sobre o Uso Programação de Jogos para Dispositivos Móveis como Recurso para o Ensino de Matemática
}

\author{
Marcelo Simas Mattos ${ }^{1,3}$, Fábio Contrera Xavier ${ }^{3}$, \\ Sérgio Crespo Coelho da Silva Pinto ${ }^{1,2}$
}

${ }^{1}$ Programa de Pós-Graduação em Engenharia de Produção e Sistemas Computacionais Universidade Federal Fluminense (UFF), Campus de Rio das Ostras - Rua Recife, s/n, Jd. Bela Vista - CEP 28895-532 - Rio das Ostras, RJ - Brasil

${ }^{2}$ Departamento de Computação - Instituto de Ciência e Tecnologia Universidade Federal Fluminense (UFF), Campus de Rio das Ostras - Rua Recife, s/n, Jd. Bela Vista - CEP 28895-532 - Rio das Ostras, RJ - Brasil

${ }^{3}$ Instituto Federal de Educação, Ciência e Tecnologia do Rio de Janeiro (IFRJ) Campus Arraial do Cabo - Arraial do Cabo - RJ - Brasil

\{marcelo.mattos, fabio.xavier\}@ifrj.edu.br, screspo@id.uff.br

\begin{abstract}
This paper presents an analysis of a learning model that uses new programming methods aimed at students from Brazilian basic education. Specifically, the model is investigated by applying of a project named Application Development as a Tool for Teaching Mathematics (DAFEMat). In this, it was planned programming courses for small games for mobile devices aimed at Brazilian High School. The courses followed an interdisciplinary proposal between Mathematics and Information Technology with a view to supporting math learning and developing Computational Thinking in students. Positive results regarding the model were verified through game developments, an applied test and the students' responses to questionnaires.
\end{abstract}

Resumo. Este artigo apresenta uma análise de um modelo de aprendizagem que se utiliza de novos métodos de programação voltados a alunos da educação básica. Especificamente, o modelo é investigado através da aplicação do Projeto de Desenvolvimento de Aplicativos como Ferramenta para o Ensino de Matemática (Projeto DAFEMat). Neste, foi planejado cursos de programação de pequenos jogos para dispositivos móveis voltados a alunos do Ensino Médio. Os cursos seguiram uma proposta interdisciplinar entre matemática e informática com vistas a apoiar o aprendizado de matemática e desenvolver o Pensamento Computacional nos estudantes. Resultados positivos referentes ao modelo foram verificados através dos desenvolvimentos dos jogos, uma prova aplicada e com as respostas dos estudantes a questionários.

\section{Introdução}

A educação, por muito tempo, foi baseada no conceito da escola tradicional, onde o foco era o conteúdo, sendo o professor o "único" detentor do saber e o aluno apenas um receptor. Porém, a educação no Brasil e no mundo tem passado por inúmeras transformações. 
VI Congresso Brasileiro de Informática na Educação (CBIE 2017)

Anais dos Workshops do VI Congresso Brasileiro de Informática na Educação (WCBIE 2017)

Tais transformações surgem no sentido de atualizar e/ou aperfeiçoar as metodologias utilizadas pelo docente no processo ensino-aprendizagem dos educandos. Por exemplo, o Exame Nacional do Ensino Médio (Enem) incentiva uma reorganização curricular, com o objetivo de desenvolver conteúdos de forma interdisciplinar e contextualizada, características incorporadas por esse exame advindas do documento que definiu as Diretrizes Curriculares Nacionais para o Ensino Médio [Conselho Nacional de Educação 2012]. Nesse âmbito, a informática torna-se um grande e indispensável apoio ao Ensino devido, entre outros predicados, a sua grande capacidade de sintetizar e facilitar o acesso e disseminação da informação. Assim, a utilização de ferramentas como, vídeo-aulas, softwares, ferramentas de busca, jogos e aplicativos, proporciona muito mais dinamismo e flexibilidade ao processo de ensino-aprendizagem.

Nesse sentido, os jogos, tantos os tradicionais (Ex: jogos de tabuleiro) como os mais modernos (Ex: aplicativos) sempre têm ocupado um espaço importante na educação por tratarem de uma forma amigável e lúdica a abordagem de conhecimentos. Por exemplo, uso de jogos digitais na educação básica tem sido investigado na área de Informática na Educação como forma de apoio ao aprendizado dos alunos em disciplinas escolares [Pereira et al. 2016]. Especificamente, a criação de jogos digitais em cursos de introdução à programação na educação básica indicam efeitos positivos para o aprendizado dos estudantes em disciplinas escolares através do desenvolvimento de habilidades próprias da computação. Além disso, pode tornar o ambiente da sala de aula mais criativo e estimulante provocando motivação e engajamento nos estudantes[Al-Bow et al. 2009].

Seguindo esta linha de pensamento, o objetivo principal desta pesquisa é apresentar e analisar um modelo de aprendizagem que se utiliza de novos métodos de ensino de programação que podem apoiar a aprendizagem na educação básica. Como objetivos específicos estão: 1) Expor e analisar o modelo de aprendizagem através da aplicação de aulas com alunos de Ensino Médio; 2) Verificar se o ensino da matemática se tornou mais atraente ao público alvo, quando os estudantes criaram pequenos jogos para dispositivos móveis com temas ligados à matemática.

A investigação ocorreu através da aplicação do Projeto de Desenvolvimento de Aplicativos como Ferramenta para o Ensino de Matemática (Projeto DAFEMat) - descrito na Seção 3. Durante o período desta investigação foram desenvolvidos aplicativos e jogos usando o MIT App Inventor 2, que é um ambiente de desenvolvimento integrado voltado para construção de aplicativos para dispositivos móveis.

\section{Modelo de aprendizagem}

O modelo de aprendizagem apresentado e analisado nesta pesquisa é fruto de estudos realizados durante a fase de planejamento do DAFEMat. Ele se baseia em algumas teorias e metodologias, que são: Teoria de aprendizagem socioconstrutivista, Problem-Based Learning (PBL) ou Aprendizagem Baseada em Problemas e a programação de jogos (ou programação com temática de games). Estes conceitos são destacados a seguir, de maneira resumida, de modo a justificar as ideias do modelo de aprendizagem.

Destaca-se da Teoria de aprendizagem socioconstrutivista que no ambiente da sala de aula o socioconstrutivismo se configura como uma teoria que considera o potencial do indivíduo na construção de seu próprio conhecimento, valorizando a sua interação com o ambiente e também com outros indivíduos [Bissolotti et al. 2014]. 
VI Congresso Brasileiro de Informática na Educação (CBIE 2017)

Anais dos Workshops do VI Congresso Brasileiro de Informática na Educação (WCBIE 2017)

Na definição de Burguillo [2010] para o PBL, o autor descreve que essa abordagem é uma estratégia instrucional centrada no estudante, na qual há trabalho colaborativo para resolução de problemas, o que se reflete em suas experiências.

Estudos que investigam o uso de criação de games em cursos introdutórios de programação têm indicado que essa investida tem se mostrado promissora em relação ao forte engajamento dos alunos e o aumento do interesse em campos de estudos relacionados à computação [Al-Bow et al. 2009, Muratet et al. 2009]. Neste tipo de investida os estudantes passam a serem sujeitos ativos na construção de suas aprendizagens.

Com base nestes conceitos e nas ideias para efetivação do DAFEMat chegou-se a algumas definições que estão no esquema da Figura 1 e são explicadas a seguir.

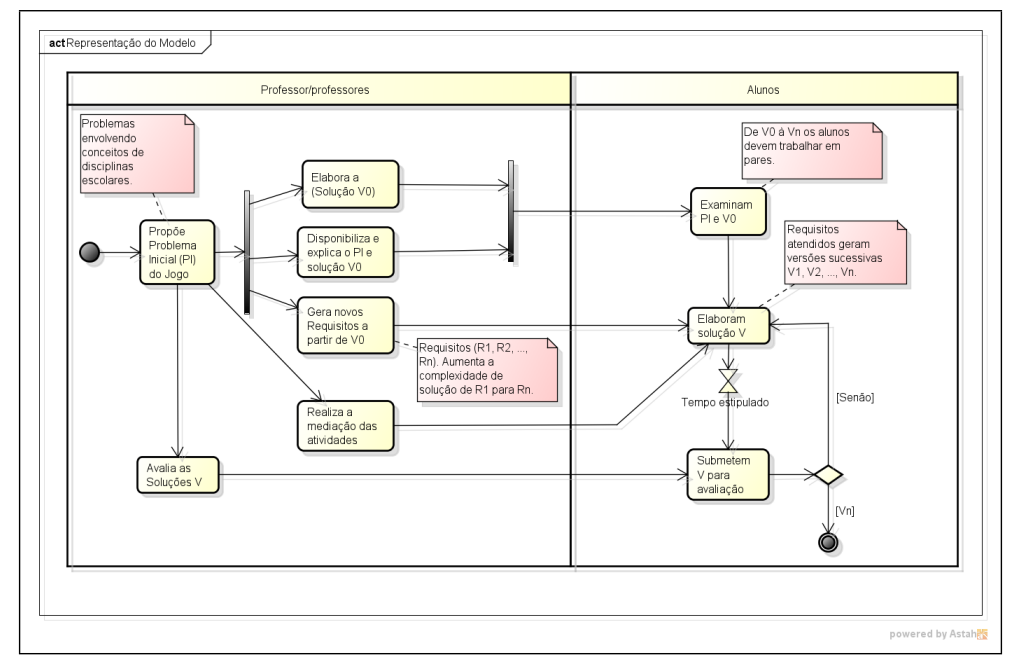

Figura 1. Representação do modelo de aprendizagem.

O problema inicial do jogo é proposto pelo professor (ou professores), se tem nesta parte do modelo a utilização de conceitos relativos à PBL. Esse problema deverá ser acompanhado de uma versão inicial do jogo (o qual já deverá ter algumas funcionalidades a serem apresentadas aos alunos), essa versão é indicada na figura como V0. Ela serve, sobretudo, para mostrar o jogo em funcionamento com as características iniciais, isso com a intenção de motivar os estudantes. Os alunos deverão acrescentar novas funcionalidades para resolver o problema inicial proposto, essas características são apresentadas aos alunos através dos chamados requisitos, sendo que, o atendimento a um grupo específicos de requisitos dão origem a versões sucessivas que são indicadas como V1, V2, ..., Vn, sendo os requisitos denominados como R1, R2, ..., Rn. Para desenvolver as versões, os estudantes devem realizar trabalhos colaborativos, o que segue ideias socioconstrutivistas. Quando os estudantes finalizam os requisitos de uma versão, eles submetem à avaliação do professor. Se a solução não for satisfatória o professor deve intervir de modo a auxiliar os alunos no entendimento dos requisitos e de forma a melhorem a versão. Deste modo o professor, além de exercer o papel de avaliador, ele também exerce a mediação durante os trabalhos dos alunos, esclarecendo dúvidas e propondo alternativas.

Em relação à aprendizagem, acredita-se que quando os alunos resolverem todos os subproblemas eles terão concluído o seu produto final e, assim, realizado uma série de processos mentais com conteúdos de programação de computadores e de disciplinas 
VI Congresso Brasileiro de Informática na Educação (CBIE 2017)

Anais dos Workshops do VI Congresso Brasileiro de Informática na Educação (WCBIE 2017)

escolares.

\section{Estudo de Caso}

A aplicação do modelo se deu através de cursos e inserido no ambiente real de sala de aula como parte integrante do projeto DAFEMat. Ocorreu em uma escola federal de ensino técnico de um município do estado do Rio de Janeiro. Contou com a aprovação da Direção de Ensino, que verificou o planejamento e a proposta apresentada. Antes de aplicar o DAFEMat no ambiente real da sala de aula, foram realizadas uma oficina e um minicurso, as suas atividades foram consideradas a primeira etapa de aplicação do projeto. A segunda etapa foi a inserção do DAFEMat nas aulas de Matemática.

Para atender à proposta de se trabalhar com alunos que a princípio não tenha conhecimentos de programação (como é o caso do público alvo do projeto) foi escolhido usar o ambiente de desenvolvimento de aplicativos para dispositivos móveis MIT App Inventor 2. É justificável o seu uso, para esse público, porque o App Inventor 2 se apresenta como uma forma inovadora de introdução à programação e à criação de app para iniciantes, a qual transforma a complexidade de linguagens de programação baseadas em texto para blocos de construção visuais, e também, dispõe de recurso arrastar e sol$\operatorname{tar}^{1}$. Outra questão sobre o App Inventor 2, que vai ao encontro da presente pesquisa, são os trabalhos publicados em âmbito nacional, que aludem resultados positivos de seu uso em ambiente escolar [Amorim et al. 2016, Finizola et al. 2014, Garcia et al. 2016, Ribeiro et al. 2016].

Durante a primeira fase ocorreu a preparação dos materiais para os alunos empregarem na programação no MIT App Inventor 2, estes foram utilizados em uma oficina nomeada pelos professores de "Oficina de App Inventor 2" e em um minicurso nomeado de "Minicurso de App Inventor 2: Criação de um jogo para dispositivos móveis".

Para a Oficina foi proposto se trabalhar com a construção de um jogo, elaborado pelos professores, que tinha como tema os conjuntos numéricos, ele foi nomeado "Bola Matemática"(Figura 2). Para iniciar sua construção os alunos receberam um tutorial com as configurações iniciais da aparência e da programação, além de figuras para serem incorporadas. Os alunos receberam, também, uma lista de requisitos a serem atendidos a cada aula (Veja a Tabela 1).

No minicurso foi pensado em aplicativos que pudessem ser realizados no período de tempo de 5 horas, previsto para o curso. Desta forma, foi planejado a criação de dois aplicativos, o aplicativo Talk to Me, presente no site oficial do App Inventor 2, e um jogo pensado pelos professores e nomeado "Salve o Banhista", que tinha como tema realizar salvamentos de um personagem representando um banhista em apuros no mar.

Para a aplicação em sala de aula foi planejado se trabalhar com dois jogos, concebidos exclusivamente para no Projeto DAFEMat, os quais estavam em consonância com a ementa da disciplina de Matemática do primeiro período do curso Técnico em Informática Integrado ao Ensino Médio (TIIEM), um é o "Dory e os ângulos" e o outro é o "Bola Matemática" (o mesmo empregado na oficina).

A "Oficina de App Inventor 2" foi aplicada nos meses de janeiro e fevereiro de 2017. Teve como público alvo alunos de primeiro e segundo períodos do curso TIIEM.

\footnotetext{
${ }^{1}$ About Us - http://appinventor.mit.edu/explore/about-us.html
} 
VI Congresso Brasileiro de Informática na Educação (CBIE 2017)

Anais dos Workshops do VI Congresso Brasileiro de Informática na Educação (WCBIE 2017)

Após os estudantes serem apresentados ao MIT App Inventor 2, terem acedido o ambiente de desenvolvimento e criado alguns aplicativos propostos no site do App Inventor $2^{2}$, eles foram apresentados ao jogo "Bola Matemática". A principais características, deste jogo, podem ser verificadas na Figura 2, percebe-se aspectos interdisciplinares, relativos à Matemática e Informática, e características próprias de jogos.

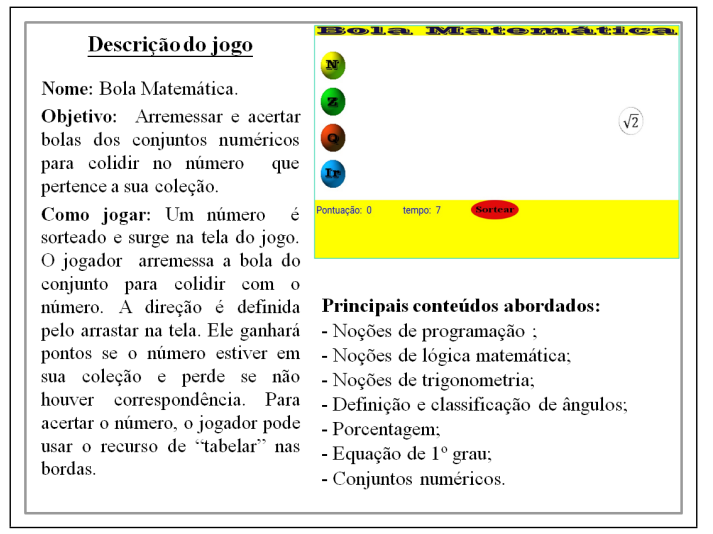

Figura 2. Descrição do Jogo "Bola Matemática".

Para o desenvolvimento deste jogo, foi pedido que os alunos se dividissem em duplas e os foi explicado qual seria a dinâmica de trabalho, esta seguia uma metodologia de programação em pares com troca de turnos [Werner et al. 2005]. Além disso, foi dito a eles que construiriam o jogo "Bola Matemática" seguindo o tutorial entregue, que ao seu término se teria todas as funcionalidades descritas e que aquela versão seria chamada de "versão zero".

Os alunos receberam, ainda, explicações que eles melhorariam o jogo a cada aula, a partir da versão 0. Para isso, foi criada uma tabela de requisitos (Tabela 1), onde o atendimento de um requisito gera nova funcionalidade para o jogo. Essa dinâmica de se melhorar o jogo a cada versão faz parte da investigação do modelo citado na Seção 1.

Tabela 1. Requisitos para o Jogo "Bola Matemática".

\begin{tabular}{|c|l|}
\hline Versão & Requisitos \\
\hline V1 & $\begin{array}{l}\text { - O jogo deve possuir uma contagem de tempo, determine 120 segundos como limite para essa fase do jogo. } \\
\text { - Faça com que quando uma bola estiver em movimento e for tocada ela deverá parar(esse requisito possibilita ao } \\
\text { jogador corrigir um lançamento errado). }\end{array}$ \\
\hline V2 & $\begin{array}{l}\text { - Aumente a quantidade de números para cada conjunto, para isso, crie pelo menos mais cinco números por conjunto. } \\
\text { - Altere a codificação para que a imagem que contém o número apareça em posições aleatórias na tela de pintura do } \\
\text { App Inventor. }\end{array}$ \\
\hline V3 & $\begin{array}{l}\text { - Ajuste o botão sortear para que ele se torne invisível logo após ser pressionado. Essa medida é para forçar o } \\
\text { jogador realizar pelo menos um arremmesso para o número sorteado. Quando houver pelo menos uma colisão com } \\
\text { o número, o botão deverá se tornar visível novamente. }\end{array}$ \\
\hline V4 & $\begin{array}{l}\text { - Acrescentar música de fundo e áudio para as colisões entre as Sprites. } \\
\text { - Crie uma figura que representará a quantidade de vidas que o jogador possui. O jogo começa com quatro vidas, o } \\
\text { jogador perderá uma vida a cada erro. Se zerar as vidas será exibida a mensagem "Gamer Over"(ou "Fim do Jogo"). } \\
\text { Introduza um áudio para cada situação. } \\
\text { - Se o tempo se esgotar e o jogador atingir 25 acertos ou mais, será exibida uma mensagem de que ele venceu a } \\
\text { fase, caso contrário será exibida mensagem de "Game over"(ou "Fim do Jogo"). Introduza áudio para cada uma das } \\
\text { situações. }\end{array}$ \\
\hline
\end{tabular}

Depois das explicações, os alunos foram convidados a criar o jogo a partir de um projeto vazio no App Inventor 2. Tiverem o suporte dos professores de Matemática e

\footnotetext{
${ }^{2}$ Tutorials for App Inventor - http://appinventor.mit.edu/explore/ai2/tutorials.html
} 
VI Congresso Brasileiro de Informática na Educação (CBIE 2017)

Anais dos Workshops do VI Congresso Brasileiro de Informática na Educação (WCBIE 2017)

Informática nas explicações sobre a sua construção e sobre os conceitos de disciplinas escolares envolvidas.

A oficina foi realizada no contraturno dos estudantes e em um período de provas. Em média, nos quatro primeiros encontros estiveram presentes aproximadamente 8 alunos e nos cinco últimos encontros em média aproximadamente 4 alunos, sendo que, no final 5 estudantes cumpriram a carga horária mínima estabelecida para o curso. Pode-se verificar que ocorreu uma evasão significativa, possivelmente ocasionada pelas dificuldades de permanecer na escola no contraturno e também devido ao período de provas destes estudantes.

Mesmo com as dificuldades apresentadas, os resultados foram positivos para os estudantes que terminaram o curso. Para exemplificar, a Figura 3 mostra a aparência final do jogo de um dos grupos e parte da programação para atender requisitos da versão 4 do jogo. Pode-se identificar na Figura 3 que os alunos encontraram como solução usar dois botões para ativar e desativar o som de fundo e cada botão tinha uma figura correspondente à situação do som. Essa solução foi discutida pela dupla para o atendimento ao requisito, contudo, eles poderiam usar apenas um único botão e trocar as imagens para cada situação, além de realizar as outras configurações. Observações como estas ou de melhorias e correções eram passados aos alunos após cada entrega de versão, os possibilitando fazer os ajustes.

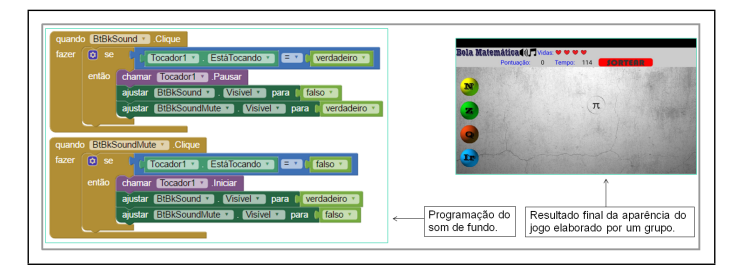

Figura 3. Programação e Aparência do Jogo finalizado por um grupo.

Próximo ao término da oficina, os cinco alunos que chegaram até o fim do curso responderam a um questionário sobre seus hábitos em relação ao uso de dispositivos móveis, o curso e sobre o App Inventor 2.

Para a presente análise foram extraídas algumas das respostas dos alunos. Em relação aos dados gerais, entres os pesquisados, 3 eram do sexo feminino e 2 do sexo masculino e eles tinham em média 16 anos de idade. Nenhum deles havia concluído algum curso de programação anterior ao curso da oficina de App Inventor 2. Entre os pesquisados apenas 1 já conhecia o App inventor 2 antes de realizar a oficina. Quanto à satisfação com a oficina $60 \%$ estavam muito satisfeitos e $40 \%$ estavam satisfeitos (as opções não marcadas eram: pouco satisfeito, insatisfeito e muito insatisfeito). Sobre o que gostavam no ambiente MIT App Inventor 2 as respostas foram: "Praticidade", "A forma de codificar através de blocos e a praticidade na criação do design", "A simplicidade.", "É simples e fácil de usar.", "O fato de ser prático e versátil.". Pode-se depreender com essas respostas que os alunos destacaram os principais pontos fortes do App Inventor 2, sendo essas características importantes para um ambiente de desenvolvimento ser usado em cursos introdutórios de programação. Quando perguntados sobre o que não gostavam no ambiente MIT App Inventor 2, as respostas foram: "O fato dele não ter muitos recursos como um programa superior", "O emulador", "Apesar de eu ter professores para me 
VI Congresso Brasileiro de Informática na Educação (CBIE 2017)

Anais dos Workshops do VI Congresso Brasileiro de Informática na Educação (WCBIE 2017)

auxiliar, a falta de um 'tutorial' ou 'guia de uso' é ruim.", "Eu gosto de tudo. Ainda não identifiquei falhas.", "Nada". Todos responderam ser muito importante para a aprendizagem deles o acompanhamento dos professores da escola durante o estudo no MIT App Inventor 2 (em uma escala que iniciava de "É ruim para o meu aprendizado" até "É muito importante para o meu aprendizado"). Quando perguntados se, na opinião deles, o curso "Oficina de MIT App Inventor 2" do projeto interdisciplinar de Informática e Matemática estaria conseguindo integrar programação/informática com conceitos da disciplina de Matemática, todos responderam que sim.

Depois que terminou a oficina iniciou-se a preparação para o "Minicurso de App Inventor 2: Criação de um jogo para dispositivos móveis". O minicurso foi aberto para a participação de toda a comunidade escolar e contou com a participação de 17 cursistas, destes 16 alunos e 1 docente, além de contar com a participação de 2 monitores do minicurso ( 2 alunos que haviam participado da oficina).

O início do minicurso seguiu a mesma dinâmica de apresentação do MIT App Inventor 2, ocorrida na oficina. Na sequência, os cursistas elaboraram como primeiro aplicativo o Talk to Me, presente no tutorial do site do App Inventor 2. O outro aplicativo que elaboraram foi o "Salve o Banhista", uma adaptação do Mole Mash (também presente no site do App Inventor 2). O objetivo do jogo é salvar o banhista o maior número de vezes possível. A sua dinâmica ocorre da seguinte forma: "a cada 1 segundo o banhista surge em posições aleatórias na tela. Ele está em apuros, para salvá-lo o jogador deve tocar na tela sobre ele para ganhar pontos, caso não toque em cima dele perderá pontos". Os principais conteúdos abordados foram: noções de programação, noções de lógica matemática, noções de trigonometria, porcentagem, equação de $1^{\circ}$ grau e área de figuras planas.

Seguindo o planejamento, após as análises dos dados coletados, das percepções dos alunos e das validações realizadas pelos professores, quanto a adequação da proposta e dos jogos aplicados na oficina e no minicurso, partiu-se para a fase dois do Projeto DAFEMat. Esta etapa foi planejada para ocorrer nos meses de abril, maio e junho de 2017 e aplicado a alunos do primeiro período do curso TIIEM.

Foi previsto para as turmas a criação de dois jogos, o "Dory e os ângulos" (Figura 4$)^{3}$, criado especificamente com base na ementa da disciplina de Matemática I do curso (TIIEM) e o "Bola Matemática", que também tinha conteúdos previstos na disciplina.

Pode-se verificar na Figura 4, através da descrição e da tela do jogo, as características lúdicas e próprias de jogos como, movimentos dos personagens, pontuação, desafio e tempo para conquistar o máximo de pontos através das escolhas. Ainda na descrição da Figura 4 se tem os principais conteúdos disciplinares abordados.

A avaliação dos alunos referente à aplicação do jogo "Dory e os ângulos" ocorreu inserido na disciplina, principalmente quando o professor de Matemática aplicou uma prova com conteúdos trabalhados por ele individualmente e os trabalhados no laboratório.

${ }^{3} \mathrm{O}$ jogo não tem fins comerciais. As imagens dos personagens Dory e Nemo foram obtidas do site da Wikia respectivamente através dos seguintes links http://findingdory.wikia.com/wiki/ File:Dory_render.png e http://pixar.wikia.com/wiki/File:Nemo.png - as imagens possuem licenças CC BY-SA. O fundo do jogo é uma fotografia extraída do site https://wWw. 360 cities.net/image/coral-reef-nursery-new-caledonia. 
VI Congresso Brasileiro de Informática na Educação (CBIE 2017)

Anais dos Workshops do VI Congresso Brasileiro de Informática na Educação (WCBIE 2017)

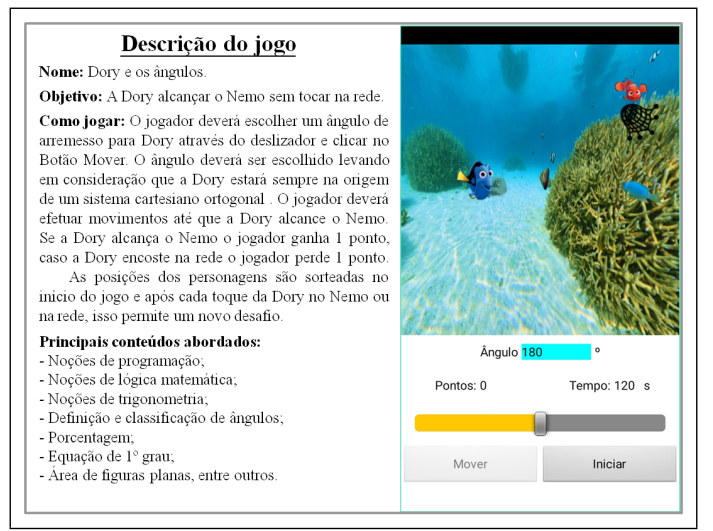

Figura 4. Descrição do Jogo "Dory e os ângulos".

A prova tinha os seguintes conteúdos: Lei Angular de Tales, Lei do ângulo externo, Teorema de Tales e Teorema das bissetrizes (interna e externa). Um destaque de uma imagem que foi usada em questão da prova está na Figura 5. A questão que usou a figura tinha o seguinte enunciado: "4) (Valor 3,0 pontos). Sabendo que $\mathrm{r} / / \mathrm{s} / / \mathrm{t}$ e que $8 \mathrm{~cm}$ equivale a $100 \%$ da altura da imagem de fundo, determine: a) A distância entre o Nemo e a rede (em $\mathrm{cm})$; b) A distância entre a Dory e o Nemo (em $\mathrm{cm})$; c) Sabendo que a distância entre o Nemo e o ponto K é 2,8 cm. Determine a distância entre a Dory e o ponto K. Obs: A reta s é a bissetriz do ângulo K."

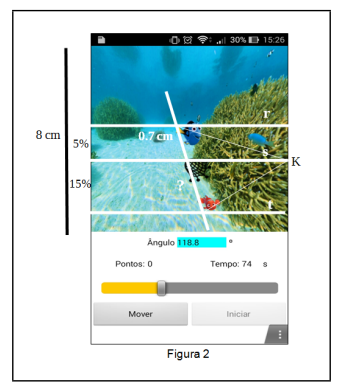

Figura 5. Figura do jogo "Dory e os ângulos" na prova.

Depois que os grupos terminaram o jogo "Dory e os ângulos" eles seguiram para a criação do jogo "Bola matemática". Para a criação deste jogo foi adotado o modelo de aprendizagem (Seção 2), nesta aplicação os alunos já receberam a "versão zero" codificada e eles foram instigados a executarem esta versão do jogo em emulador ou em seus dispositivos móveis. Na sequência das aulas, os estudantes foram aperfeiçoando os jogos seguindo os requisitos propostos (Tabela 1). No último encontro do DAFEMat os alunos foram convidados a responderem um questionário (de forma voluntária) que tinham questões semelhantes às aplicadas durante a oficina. Este obteve o retorno de trinta e quatro alunos o que representou $79 \%$ do total. As principais respostas para a análise apresentada neste artigo são indicadas a seguir.

Os pesquisados tinham entre $15(22,65 \%)$ e $16(12,35 \%)$ anos de idade, 14 (41\%) eram do sexo feminino e 20 (59\%) do sexo masculino. Apenas $3(8,8 \%)$ estudantes já haviam concluído algum curso de programação. Quando questionados sobre o uso do MIT App Inventor 230 (88,2\%) pesquisados informaram que não conheciam o ambi- 
VI Congresso Brasileiro de Informática na Educação (CBIE 2017)

Anais dos Workshops do VI Congresso Brasileiro de Informática na Educação (WCBIE 2017)

ente, $3(8,8 \%)$ responderam que já conheciam e 1(2,9\%) não respondeu a questão. Sobre o acompanhamento dos professores da escola durante o estudo no MIT App Inventor 2, $52,4 \%$ (18) dos pesquisados consideraram como muito importante para o aprendizado deles, $41,2 \%$ (14) consideraram importante para o aprendizado deles e 2,9\% (1) considerou desimportante para o aprendizado dele e 1 pesquisado não respondeu. Os recursos de programação do MIT App Inventor 2 foi considerada pela maioria dos pesquisados como bom $(25,73,5 \%)$ e excelente $(6,17,6 \%), 3(8,8 \%)$ pesquisados consideraram como regular. Para o nível de satisfação deles com as atividades interdisciplinares entre Informática e Matemática do DAFEMat, a maioria dos pesquisados estavam satisfeitos (24, 70,6\%), seguido pelos muito satisfeitos $(8,23,5 \%)$ e os pouco satisfeitos $(2,5,9 \%)$. Na opinião deles o DAFEMat está conseguindo integrar programação/informática com conceitos de Matemática $(32,94,1 \%)$, apenas $1(2,9 \%)$ pesquisado opinou ao contrário e um outro não respondeu. Em uma questão da última seção do questionário foi pedida a opinião dos estudantes sobre o que eles tinham achado da proposta de realizar melhorias, a cada versão, no jogo "Bola Matemática". Nela, eles ainda foram questionados se essa proposta havia sido útil para o aprendizado em Matemática e em Informática. Todos os estudantes que responderam a esta questão $(32,94,1 \%)$ descreveram de forma positiva sobre o modelo. As justificativas podem ser sintetizadas nos seguintes pontos: desenvolvimento de aprendizagem; ajuda em relação à matemática e informática; autonomia dos estudantes no desenvolvimento dos aplicativos; foi útil a forma gradual de aumentar a complexidade na criação dos jogos; ajudou na hora de realizar a prova; ajudou na compreensão sobre conjuntos numéricos; evolução do estudante a cada versão; aumento na vontade de estudar; uso de algo próximo aos estudantes, como os jogos, na integração com a disciplina de matemática; estímulo do raciocínio lógico e do trabalho em equipe; desafio da capacidade de pensamento lógico e de conhecimentos matemáticos; desenvolvimento do pensamento lógico.

\section{Conclusão}

O primeiro objetivo específico foi atingido, pois no artigo apresentou como pode ser trabalhada a construção de jogos para dispositivos móveis de maneira contextualizada com o público alvo (estudantes do Ensino Médio), a disciplina de Matemática e planos pedagógicos. Na construção dos jogos os alunos realizavam melhorias sucessivas em cumprimento aos requisitos pedidos, realizavam os trabalhos de forma colaborativa e contavam com a mediação dos professores de Matemática e Informática. Além disso, para completar os requisitos precisaram desenvolver o Pensamento Computacional. Por exemplo, usaram esse tipo de pensamento para escolher os blocos certos e encaixá-los na sequência correta, para ter novas funcionalidades no jogo.

$\mathrm{Na}$ verificação do segundo objetivo específico, pode-se depreender com base nas respostas aos dois questionários, que há indicação que o modelo se apresenta promissor, no sentido de tornar o ensino da matemática mais atraente a alunos do Ensino Médio. Isso porque, os alunos que chegaram a até o fim da oficina de App Inventor 2 declararam estarem muito satisfeitos (60\%) e satisfeitos (40\%), e na aplicação em sala de aula a maioria dos pesquisados estavam satisfeitos $(24,70,6 \%)$, seguido pelos muito satisfeitos $(8,23,5 \%)$ e os pouco satisfeitos $(2,5,9 \%)$. Além disso, de uma forma geral, os alunos julgaram ser importante a participação dos professores e responderam positivamente sobre a interdisciplinaridade do DAFEMat. Contribui ainda, com essa indicação, a criação por 
VI Congresso Brasileiro de Informática na Educação (CBIE 2017)

Anais dos Workshops do VI Congresso Brasileiro de Informática na Educação (WCBIE 2017)

completo do jogo "Bola Matemática" realizada pelos alunos na oficina e na aplicação no ambiente de sala de aula, e o jogo "Dory e os ângulos" realizados pelos alunos das duas turmas do primeiro período do curso TIIEM.

Como proposta de trabalhos futuros, pode-se planejar trabalhar com DAFEMat em outras escolas de Ensino Médio que não sejam nomeadamente escolas de ensino médio integrado ao ensino técnico.

\section{Referências}

Al-Bow, M., Austin, D., Edgington, J., Eajardo, R., Fishburn, J., Lara, C., Leutenegger, S., and Meyer, S. (2009). Using game creation for teaching computer programming to high school students and teachers. Proceeding ITiCSE'09 Proceedings of the 14th annual ACM SIGCSE conference on Innovation and technology in computer science education, 41(3):104-108.

Amorim, J., Silva, N., Santos, M. S., and Santos, F. D. (2016). Integrando as Plataformas App Inventor e Arduino na Construção de um Humanoide. Anais do Workshop de Informática na Escola, 22(1):786.

Bissolotti, K., Garcia, H., and Pareira, A. T. C. (2014). Potencialidades das mídias sociais e da gamificação na educação a distância. CINTED - Novas Tecnologias na Educação.

Burguillo, J. C. (2010). Using game theory and competition-based learning to stimulate student motivation and performance. Computers and Education, 55(2):566 - 575.

Conselho Nacional de Educação, C. (2012). Resolução Nº 2, De 30 De Janeiro 2012. Ministério da Educação, 2012:1-9.

Finizola, A. B., Henning, E., Raposo, S., Pacheco, M. B., Pereira, N., Gomes, W. S., Liz, A., Araújo, S. O. D., and Souza, V. C. (2014). O ensino de programação para dispositivos móveis utilizando o MIT-App Inventor com alunos do ensino médio. $20^{\circ}$ Workshop de Educação em Informática, (Cbie):337-341.

Garcia, V. R., da Silva, D. O., de Oliveira, I. G., Trindade, D. D. F. G., Sgarbi, E. M., and do Nascimento, L. F. L. (2016). Despertando Jovens Talentos com o Conhecimento da Computação. Anais do Workshop de Informática na Escola, 22(1):583.

Muratet, M., Torguet, P., Jessel, J. P., and Viallet, F. (2009). Towards a serious game to help students learn computer programming. International Journal of Computer Games Technology, 2009(1).

Pereira, A. B., Piconez, S., Zimmer, J., and da Silva, F. S. C. (2016). Jogos Digitais no desenvolvimento de conceitos matemáticos sob perspectiva BYOD e abordagem mLearning na escola pública. Anais do Workshop de Informática na Escola, 22(1):71.

Ribeiro, J. P., Manso, M. A., and Borges, M. (2016). Dinâmicas com App Inventor no Apoio ao Aprendizado e no Ensino de Programação. Anais do Workshop de Informática na Escola, 22(1):271.

Werner, L. L., Campe, S., and Denner, J. (2005). Middle school girls + games programming $=$ information technology fluency. In Proceedings of the 6th Conference on Information Technology Education, SIGITE '05, pages 301-305, New York, NY, USA. ACM. 